Article

\title{
Bone Marrow CX3CL1/Fractalkine is a New Player of the Pro-Angiogenic Microenvironment in Multiple Myeloma Patients
}

\author{
Valentina Marchica ${ }^{1}$, Denise Toscani ${ }^{1}$, Anna Corcione ${ }^{2}$, Marina Bolzoni ${ }^{1}$, Paola Storti ${ }^{1}$, \\ Rosanna Vescovini ${ }^{1}$, Elisa Ferretti ${ }^{3}$, Benedetta Dalla Palma 1,4, Emanuela Vicario ${ }^{1}$, \\ Fabrizio Accardi ${ }^{1,4}$, Cristina Mancini ${ }^{5}$, Eugenia Martella ${ }^{5}$, Domenico Ribatti ${ }^{6} \mathbb{D}_{\text {, Angelo Vacca }}{ }^{7}$, \\ Vito Pistoia ${ }^{8}$ and Nicola Giuliani ${ }^{1, *(1)}$ \\ 1 Department of Medicine and Surgery, University of Parma, 43126 Parma, Italy; \\ valentina.marchica@unipr.it (V.M.); denise.toscani@gmail.com (D.T.); marina.bolzoni@unipr.it (M.B.); \\ paola.storti@unipr.it (P.S.); rosanna.vescovini@unipr.it (R.V.); benedetta.dallapalma@gmail.com (B.D.P.); \\ emanuela_vicario@hotmail.it (E.V.); accardi.fabrizio@gmail.com (F.A.) \\ 2 Center for Autoinflammatory Diseases and Immunedeficiencies, IRCCS "Istituto Giannina Gaslini", \\ 16147 Genoa, Italy; annacorcione@gaslini.org \\ 3 Center of Excellence for Biomedical Research (CEBR), University of Study of Genoa, 16132 Genoa, Italy; \\ elisaferretti@gaslini.org \\ 4 Hematology, “Azienda Ospedaliero-Universitaria di Parma”, 43126 Parma, Italy \\ 5 “U.O. di Anatomia Patologica, Azienda Ospedaliero-Universitaria di Parma”, 43126 Parma, Italy; \\ cmancini@ao.pr.it (C.M.); emartella@ao.pr.it (E.M.) \\ 6 Department of Basic Medical Sciences, Neurosciences and Sensory Organs, University of Bari, 70124 Bari, \\ Italy; domenico.ribatti@uniba.it \\ 7 Department of Biomedical Science and Human Oncology, University of Bari, 70124 Bari, Italy; \\ angelo.vacca@uniba.it \\ 8 Immunology Area, “Ospedale Pediatrico Bambino Gesù”, 00165 Roma, Italy; vito.pistoia@opbg.net \\ * Correspondence: nicola.giuliani@unipr.it; Tel.: +39-0521033299
}

Received: 6 February 2019; Accepted: 28 February 2019; Published: 6 March 2019

\begin{abstract}
C-X3-C motif chemokine ligand 1 (CX3CL1)/fractalkine is a chemokine released after cleavage by two metalloproteases, ADAM metallopeptidase domain 10 (ADAM10) and ADAM metallopeptidase domain 17 (ADAM17), involved in inflammation and angiogenesis in the cancer microenvironment. The role of the CX3CL1 / C-X3-C motif chemokine receptor 1(CX3CR1) axis in the multiple myeloma (MM) microenvironment is still unknown. Firstly, we analyzed bone marrow (BM) plasma levels of CX3CL1 in 111 patients with plasma cell disorders including 70 with active $\mathrm{MM}, 25$ with smoldering myeloma (SMM), and 16 with monoclonal gammopathy of undetermined significance (MGUS). We found that BM CX3CL1 levels were significantly increased in MM patients compared to SMM and MGUS and correlated with BM microvessel density. Secondly, we explored the source of CX3CL1 in MM and BM microenvironment cells. Primary CD138 ${ }^{+}$cells did not express CXC3L1 but up-regulated its production by endothelial cells (ECs) through the involvement of tumor necrosis factor alpha (TNF $\alpha)$. Lastly, we demonstrated the presence of CX3CR1 on BM CD14 ${ }^{+} \mathrm{CD} 16^{+}$ monocytes of MM patients and on ECs, but not on MM cells. The role of CX3CL1 in MM-induced angiogenesis was finally demonstrated in both in vivo chick embryo chorioallantoic membrane and in vitro angiogenesis assays. Our data indicate that CX3CL1, present at a high level in the BM of MM patients, is a new player of the MM microenvironment involved in MM-induced angiogenesis.
\end{abstract}

Keywords: multiple myeloma; angiogenesis; inflammation; CX3CL1/fractalkine; microenvironment 


\section{Introduction}

Tumor-promoting inflammation and angiogenesis are hallmarks of cancer [1]. Multiple myeloma $(\mathrm{MM})$ is a hematological malignancy characterized by the tight dependence of malignant plasma cells (PCs) on the bone marrow (BM) microenvironment $[2,3]$. These relationships activate the production of several pro-inflammatory cytokines, chemokines and growth factors supporting MM cell survival, bone destruction, and an increased BM angiogenesis [4-7] that typically correlates with disease stage and prognosis [8-10].

C-X3-C motif chemokine ligand 1 (CX3CL1), also known as fractalkine, is a protein of 373 amino acids with three main domains: Chemokine, mucin-like stalk, and transmembrane [11]. In particular, the mucin-like domain contains a cutting site allowing the metalloproteases ADAM metallopeptidase domain 10 (ADAM10) and ADAM metallopeptidase domain 17 (ADAM17) to cleave and release the protein in a soluble form [12,13]. Indeed, CX3CL1 can be also found as a membrane-bound protein. By binding to its only receptor C-X3-C motif chemokine receptor 1 (CX3CR1), CX3CL1 plays a role in both chemotaxis and cell adhesion, especially in endothelial cells (ECs) [14,15]. In both cancer and inflammation processes, CX3CL1 has been shown to stimulate chemotaxis, recruiting cells that expressed CX3CR1, such as natural killer (NK) cells, dendritic cells (DCs), and monocytes [16-18]. Moreover, CX3CL1 induces angiogenic potential in CX3CR1-expressing monocytes. CX3CL1 activates the SRC/focal adhesion kinase (FAK) signaling pathway in cancer cells regulating their migration and invasion [19,20] and facilitates bone metastasis of CX3CR1-expressing tumor cells [21,22].

The pathophysiological role of the CX3CL1/CX3CR1 axis in the interaction between tumor cells and the microenvironment has been demonstrated in several solid tumors, such as breast and prostate and in different types of B cell lymphomas and chronic lymphocytic leukemia [11]. A possible involvement of CX3CR1 in the cross talk between neoplastic B cells and the tumor microenvironment has been proposed since CX3CL1 and CX3CR1 are co-expressed on different types of B malignant cells. Recently, it has also been reported that the CX3CL1/CX3CR1 axis could be involved in the stimulation of $\mathrm{MM}$ cell adhesion to the extracellular matrix and the production of soluble factors that promote osteoclast differentiation [23]. However, the pathophysiological role of the CX3CL1/CX3CR1 axis in the MM microenvironment is still unexplored. In the present study, we analyzed the BM levels of CX3CL1 in a large cohort of patients with MM and indolent monoclonal gammopathies, and we identified the CX3CL1/CX3CR1 axis as a new player of the vascular microenvironment involved in MM-induced angiogenesis.

\section{Results}

\subsection{CX3CL1 Bone Marrow Plasma Levels Increase across the Progression of Multiple Myeloma Disease}

We firstly evaluated BM CX3CL1 levels in our cohort of 111 patients, including 16 patients with monoclonal gammopathy of undetermined significance (MGUS), 25 with smoldering myeloma (SMM), and 70 with active MM, and 10 healthy donors (HD) as controls. BM CX3CL1 levels significantly increased across the groups of subjects analyzed (median range BM CX3CL1 level in $\mathrm{HD}=0.560(0.420-0.730) \mathrm{ng} / \mathrm{mL} ; \mathrm{MGUS}=0.665(0.435-0.902) \mathrm{ng} / \mathrm{mL} ; \mathrm{SMM}=0.720(0.398-2.090)$ $\mathrm{ng} / \mathrm{mL} ; \mathrm{MM}=1.008$ (0.394-0.230) ng/mL) $(P<0.0001$, Kruskal-Wallis test). Specifically, CX3CL1 levels were significantly increased in the BM plasma of MM patients compared to HD, MGUS, and SMM patients $(P<0.0001, P<0.0001$, and $P=0.0011$ respectively, Mann-Whitney test) (Figure $1 \mathrm{~A})$. Based on the International Staging System (ISS), we found that MM patients with ISS III had higher CX3CL1 BM levels as compared to those with ISS I and ISS II, as shown in Figure $1 \mathrm{~B}(P=0.0001$ and $P<0.0001$, Mann-Whitney test) (median range BM CX3CL1 level in ISS I = $0.770(0.46-1.530) \mathrm{ng} / \mathrm{mL}$; $\mathrm{II}=0.71(0.394-1.460) \mathrm{ng} / \mathrm{mL}$; and III = $1.38(0.53-2.23) \mathrm{ng} / \mathrm{mL})$. Moreover, BM soluble CX3CL1 levels were positively correlated with the percentage (\%) of BM PCs checked by flow cytometry in the BM aspirates $(P<0.0001, r=0.44$, Spearman's correlation) (Figure $1 C)$. On the other hand, any significant correlation was not observed between the BM CX3CL1 plasma levels with the presence of osteolytic 
lesions ( $P=0.34$, not significant NS, Supplemental Figure S1A) or the presence of high bone disease (HBD) compared to low bone disease (LBD) $(P=0.78, \mathrm{NS})$ in MM patients (Supplemental Figure S1B).

A)

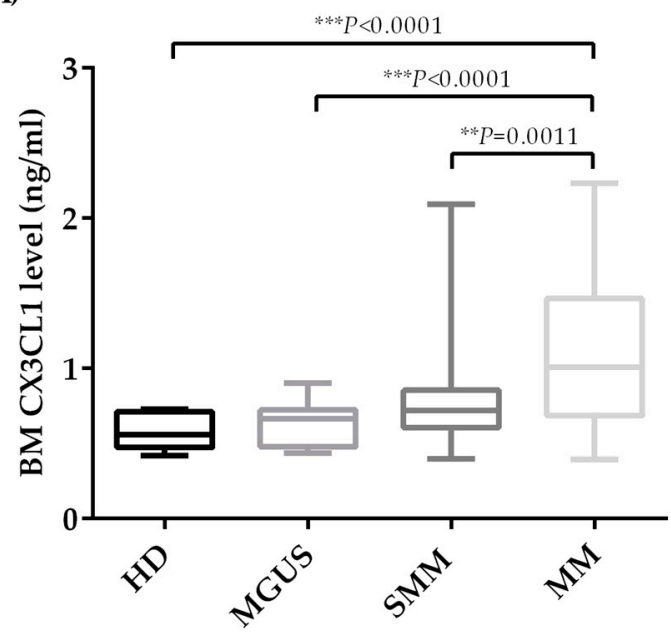

C)

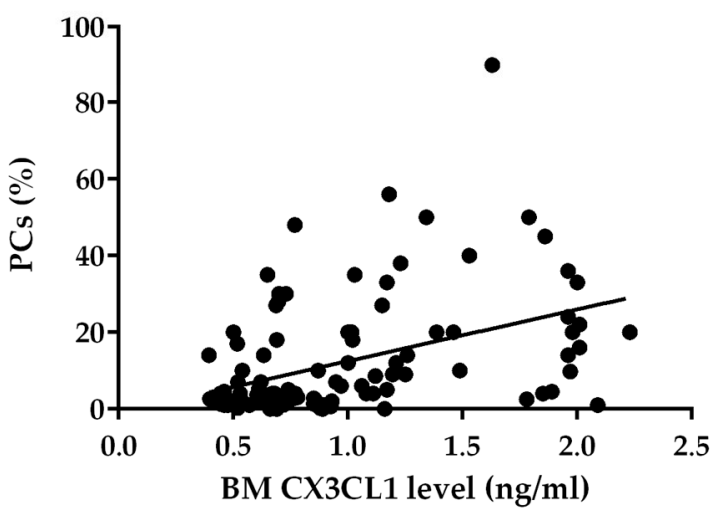

B)

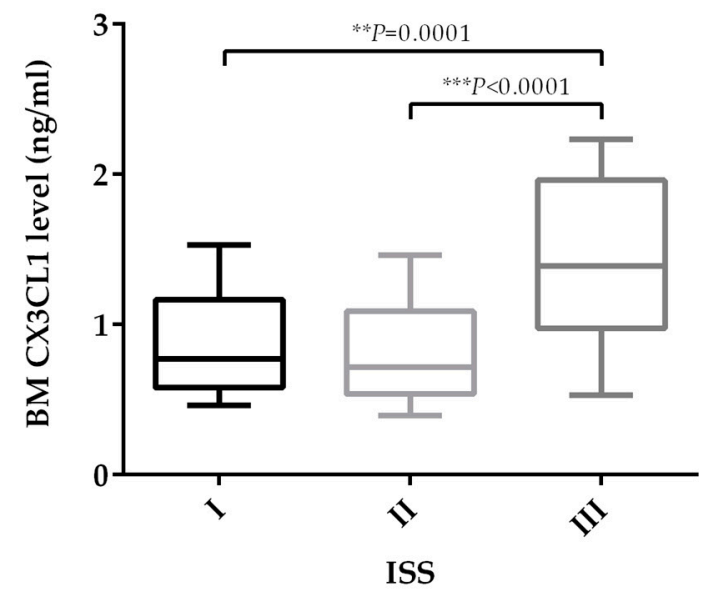

D)

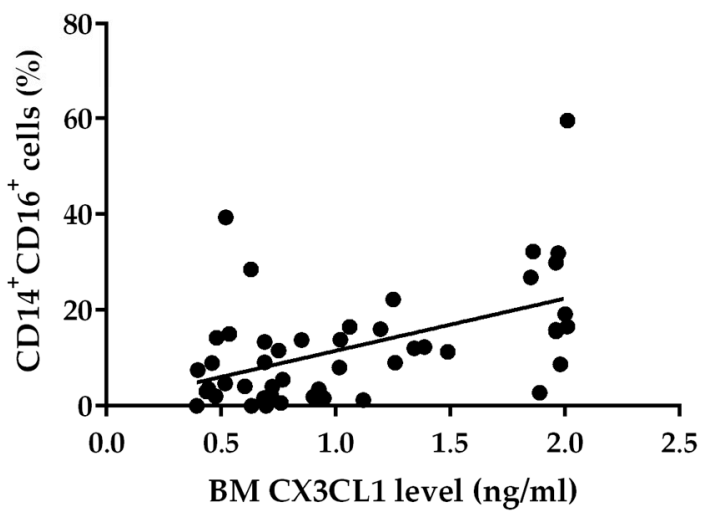

Figure 1. BM levels of CX3CL1 in patients with monoclonal gammopathies. (A) Box plots represent the median levels of CX3CL1 ( $\mathrm{ng} / \mathrm{mL})$ evaluated in BM plasma obtained from patients with MGUS $(\mathrm{n}=16), \operatorname{SMM}(\mathrm{n}=25), \mathrm{MM}(\mathrm{n}=70)$, and HD $(\mathrm{n}=10)$ ( $P$ value calculated by Mann-Whitney test). (B) Box plots represent the median levels of BM CX3CL1 in patients with active MM grouped by the ISS stage I $(\mathrm{n}=17)$, II $(\mathrm{n}=20)$, and III $(\mathrm{n}=33)$ ( $P$ value calculated by Mann-Whitney test). (C) Scatter plots showing the correlation between CX3CL1 BM plasma levels and percentage of BM PCs obtained from the BM aspirate of 105 patients with monoclonal gammopathies by flow-cytometry analysis ( ${ }^{* * *} P<0.0001, \mathrm{r}=0.44$ calculated by Spearman's correlation). (D) Scatter plots show a significant positive correlation between CX3CL1 levels in BM plasma obtained from 48 patients with monoclonal gammopathies and percentage of $\mathrm{CD} 14^{+} \mathrm{CD} 16^{+}$monocytes evaluated by flow cytometry ( ${ }^{* *} P=0.0006, \mathrm{r}=0.48$ calculated by Spearman's correlation). CX3CL1-C-X3-C motif chemokine ligand 1; MUGS —-monoclonal gammopathy of undetermined significance; HD—healthy donors; SMM—smoldering myeloma; MM-multiple myeloma; BM-bone marrow; PC-plasma cell; ISS-International Staging System.

Moreover, since the monocytic subset $\mathrm{CD} 14^{+} \mathrm{CD} 16^{+}$shares both pro-osteoclastogenic and angiogenic properties and increased in $\mathrm{MM}$ patients compared to patients with asymptomatic disease [24,25], we analyzed the possible correlation between BM CX3CL1 levels and CD14 CD16 ${ }^{+}$ cells. Interestingly, we found that BM CX3CL1 levels positively correlated with the percentage of BM $\mathrm{CD} 14^{+} \mathrm{CD} 16^{+}$monocytes (Figure 1D) $(P=0.0006, \mathrm{r}=0.48$, Spearman's correlation) in the sub-cohort of the patients analyzed (7 MGUS, 10 SMM, and $31 \mathrm{MM}$ ). A multivariate analysis confirmed that CX3CL1 
BM levels significantly correlated with the percentage of both PCs $(P=0.003)$ and BM CD14 ${ }^{+} \mathrm{CD} 16^{+}$ monocytes $(P=0.0001)$.

\subsection{Bone Marrow CX3CL1 Levels Correlate with Bone Marrow Vascularization in Multiple Myeloma Patients}

On the basis of the well-known involvement of CX3CL1 in angiogenesis [26], we sought to determine whether MM BM CX3CL1 levels could be related to BM angiogenesis. Interestingly, the number of CD34 ${ }^{+}$vessels significantly positively correlated with BM CX3CL1 levels in MM patients $(P=0.0019, \mathrm{r}=0.57$, Spearman's correlation) (Figure 2A). Representative immunohistochemical CD34 staining of MM patients with high and low BM CX3CL1 levels is reported in Figure 2B. Similar to that observed with BM aspirates, we also found that BM soluble CX3CL1 levels significantly positively correlated with the number of BM PCs in bone biopsies (Figure 2C) $(P=0.0013, r=0.58$, Spearman's correlation). Multivariate analysis showed that BM microvessel density (MVD) significantly correlated with the number of PCs $(P=0.0001)$ and with the BM CX3CL1 levels even though statistical significance was not reached $(P=0.08)$.

A)

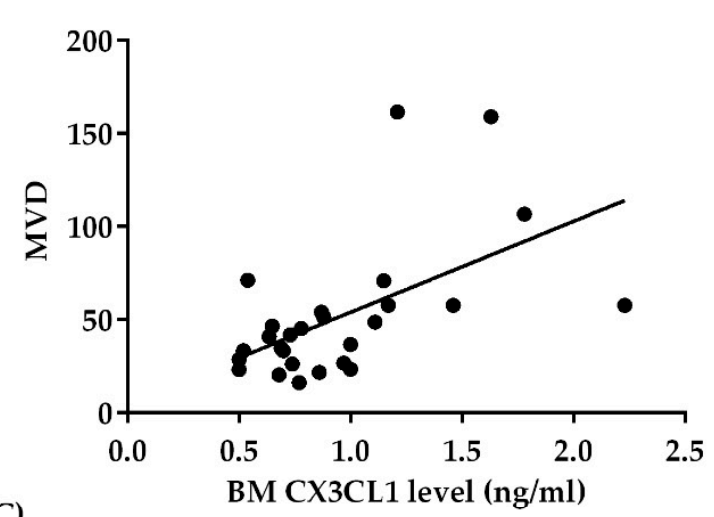

C)

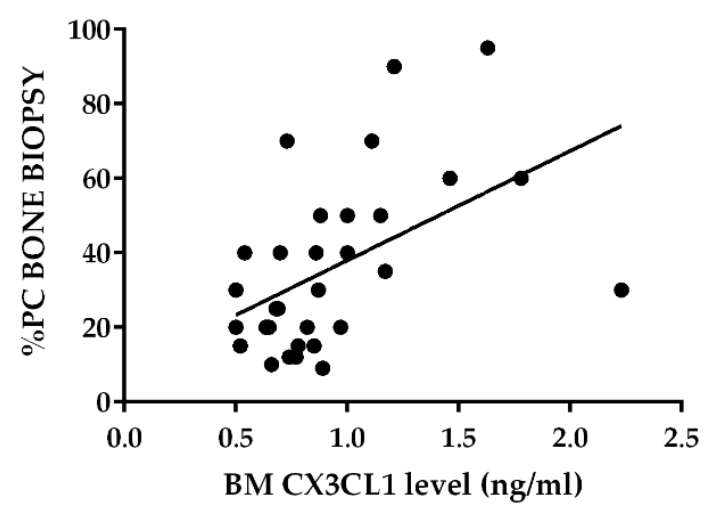

B)
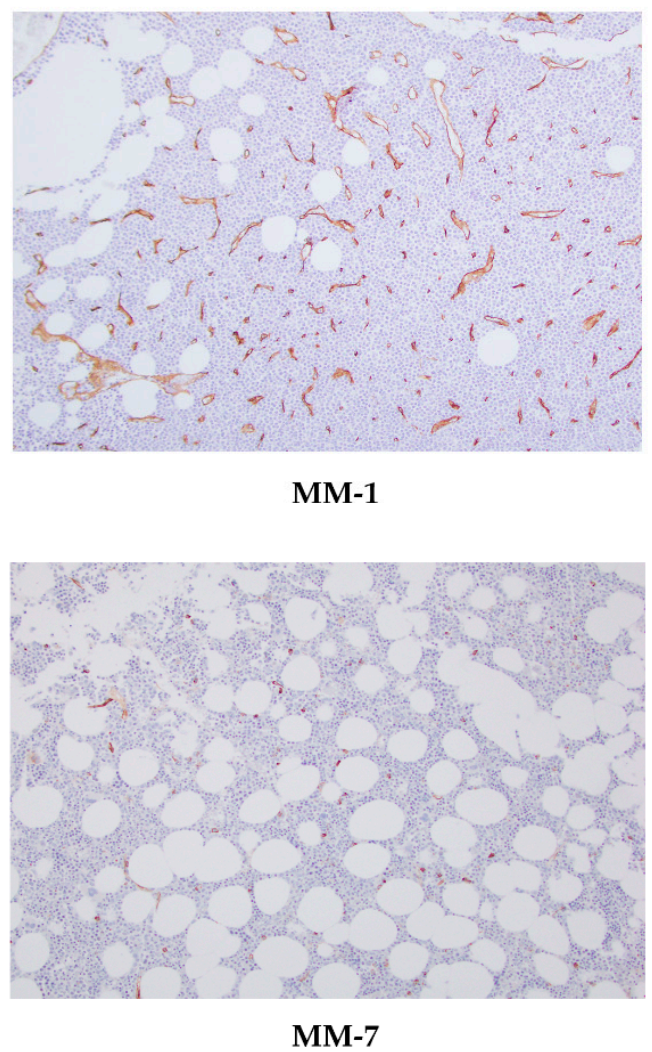

Figure 2. BM CX3CL1 correlates with MVD in MM patients. (A) The graph shows a significant positive correlation between CX3CL1 levels in BM plasma obtained from 27 MM patients and MVD, evaluated as CD $34^{+}$cells $/ \mathrm{mm}^{2}$ by immunohistochemistry $(\mathrm{IHC})\left({ }^{* *} P=0.0019, \mathrm{r}=0.57\right.$ calculated by Spearman's correlation). (B) The pictures show the BM CD34 staining in IHC of two representative MM patients with high (MM-1) and low (MM-7) BM CX3CL1 levels. Original magnification 10×. (C) The graph displays the correlation between CX3CL1 BM plasma levels and percentage of PCs by IHC from bone biopsies obtained from $27 \mathrm{MM}$ patients $\left({ }^{* *} P=0.0013, \mathrm{r}=0.58\right.$ calculated by Spearman's correlation). MVD-microvessel density; IHC-immunohistochemistry. 
2.3. CX3CL1 Is Released by Endothelial Cells in the Presence of Multiple Myeloma Cells: Role of Human Tumor Necrosis Factor Alpha

To unveil the source of the high BM CX3CL1 levels in MM patients, we analyzed CX3CL1 mRNA expression by primary CD138 ${ }^{+}$cells and human myeloma cell lines (HMCLs) in public datasets (GSE16122) (GSE6205). Primary CD138 ${ }^{+}$cells and HMCLs expressed CX3CL1 (Figure 3A) mRNA at low levels, with no statistical differences between HD, MGUS, MM, plasma cell leukemia (PCL), and HMCLs. Likewise, western blotting analysis revealed the absence of CX3CL1 protein in primary $\mathrm{CD}_{138^{+}}$cells from four newly diagnosed MM (MM-ND) and four relapsed MM (MM-R) patients (Figure 3B upper panel) and in seven HMCLs (JJN3, OPM2, U266, INA6, XG1, MM1S, and RPMI 8226) (Figure 3B lower panel).

A)

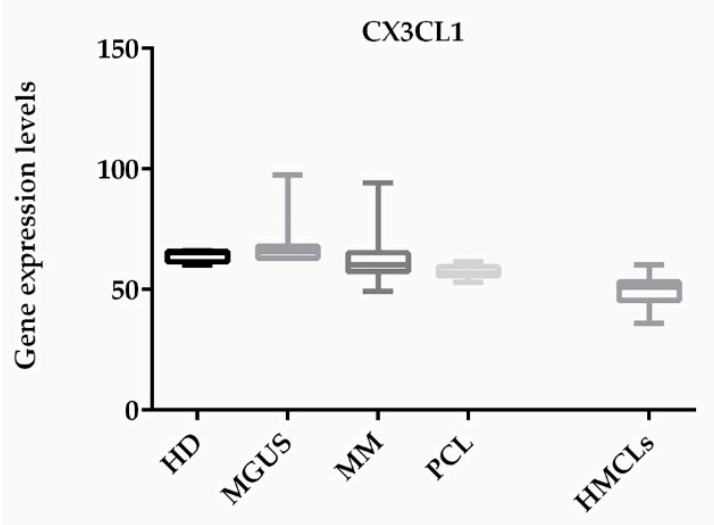

B)

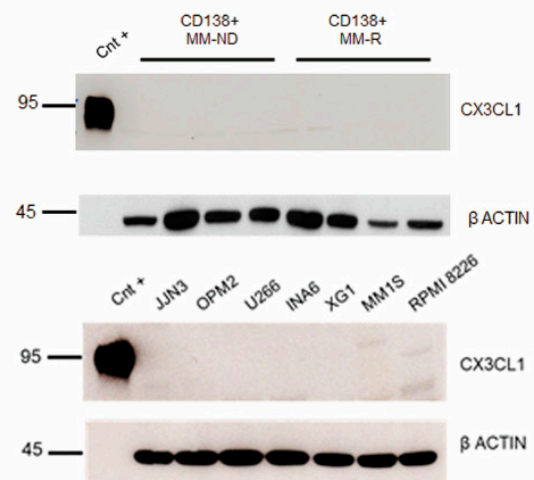

C)

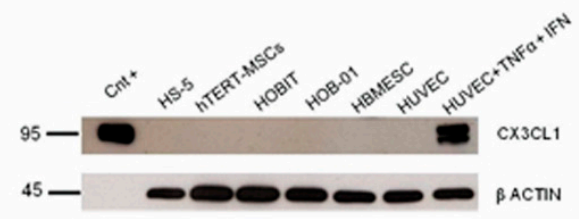

Figure 3. (A) CX3CL1 expression by MM cells. Box plots of the expression levels of CX3CL1 mRNA in CD138 ${ }^{+}$cells obtained from 4 HD, 11 MGUS, 133 MM patients, 9 PCL (GSE16122), and 23 HMCLs (GSE6205). (B) The expression of CX3CL1 protein was evaluated in eight purified BM CD138+ (upper) samples from four MM-ND and four MM-R patients and in seven HMCLs (lower) by western blot (positive control (Cnt+): Recombinant CX3CL1). (C) The western blot represents CX3CL1 protein expression on microenvironment cell lines. MM-ND—newly diagnosed MM; MM-R—relapsed MM; PCL_-plasma cell leukemia; HMCLs—human myeloma cell lines; hTERT-MSC—human telomerase reverse transcriptase transduced mesenchymal stromal cell line; HBMESC-human BM-derived endothelial stem cells.

Subsequently, we investigated the expression of CX3CL1 by osteoblast, osteocyte, mesenchymal, and EC lines and, as reported in Figure 3C, we showed a lack of CX3CL1 protein expression by western blot analysis. On the other hand, in our experiment setting and according to literature data $[27,28]$, human umbilical vein endothelial cells (HUVEC) produced high levels of CX3CL1 protein when stimulated with the pro-inflammatory cytokines, tumor necrosis factor alpha (TNF $\alpha)(50 \mathrm{ng} / \mathrm{mL})$ and interferon gamma (IFN $\gamma)(10 \mathrm{ng} / \mathrm{mL})$, for $24 \mathrm{~h}$ (Figure 3C).

It is well known that MM cells produced pro-inflammatory cytokines, such as TNF $\alpha$ [29]. For this reason, we explored the ability of MM cells to increase the production of CX3CL1 by treating ECs with the conditioned media (CM) of the HMCLs (OPM2, JJN3, and MM1S). We firstly showed that neither ECs nor HMCLs produce detectable levels of soluble CX3CL1 after $24 \mathrm{~h}$ (Figure 4A). Interestingly, the treatment of ECs with the CM of HMCLs significantly increased the production of soluble CX3CL1 
compared to HUVECs and human BM-derived endothelial stem cells (HBMESCs) alone, as shown in Figure 3A (HUVEC + CM JJN3 vs. control (Cnt) $P<0.0001 ;$ HUVEC + CM OPM2 vs. Cnt $P<0.0001$; HUVEC + CM MM1S vs. Cnt $P=0.0003$, Student's $t$-test) and Figure 4B (HBMESC + CM JJN3 vs. Cnt $P=0.0007$; HBMESC + CM OPM2 vs. Cnt $P=0.0002 ;$ HBMESC + CM MM1S vs. Cnt $P=0.0006$, Student's $t$-test). In the same experimental setting, the treatment with anti-TNF $\alpha$ neutralizing antibody $(2.7 \mu \mathrm{g} / \mathrm{mL})$ for $24 \mathrm{~h}$ significantly inhibited the production of CX3CL1 by ECs induced by CM HMCLs. (HUVEC: CM JJN3 vs. CM JJN3 + anti-TNF $\alpha P<0.0001 ;$ CM OPM2 vs. CM OPM2 + anti-TNF $\alpha$ $P<0.0001 ; \mathrm{CM}$ MM1S vs. CM MM1S + anti-TNF $\alpha P=0.0004$, Student's $t$-test) (HBMESC: CM JJN3 vs. CM JJN3 + anti-TNF $\alpha P<0.0001 ;$ CM OPM2 vs. CM OPM2 + anti-TNF $\alpha P<0.0001 ;$ CM MM1S vs. CM MM1S + anti-TNF $\alpha P<0.0001$, Student's $t$-test) (Figure 4A,B).

A)

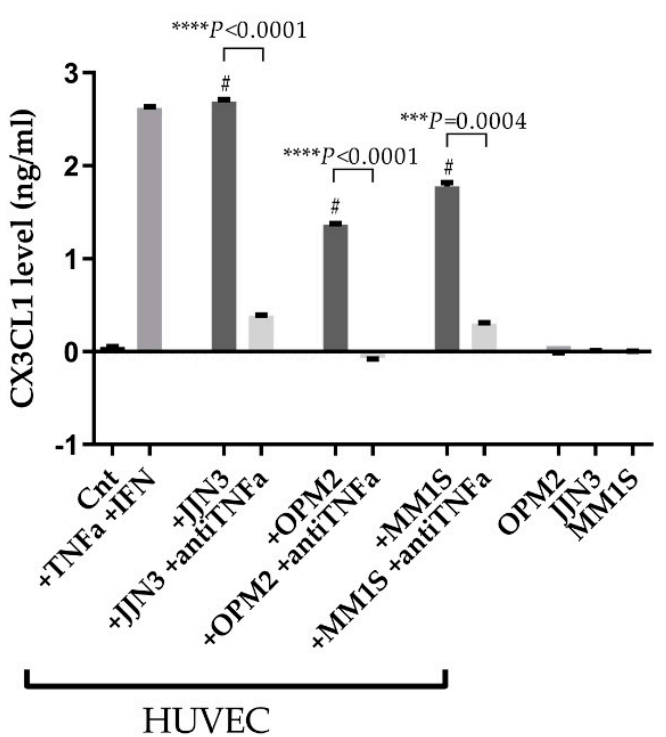

B)

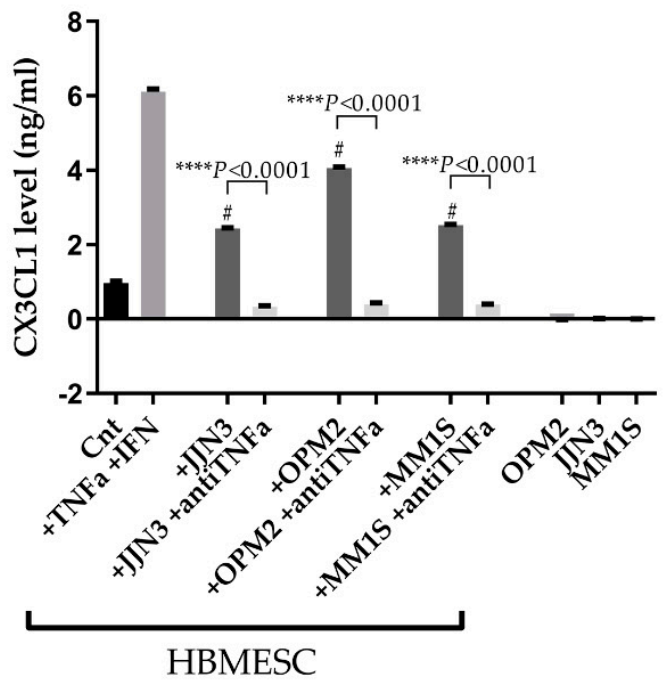

Figure 4. MM cells increase the angiogenic activity of ECs through CX3CL1 production. HUVEC (A) and HBMESC (B) were treated for $24 \mathrm{~h}$ with $\mathrm{TNF} \alpha(50 \mathrm{ng} / \mathrm{mL})$ and $\mathrm{IFN} \gamma(10 \mathrm{ng} / \mathrm{mL})$, as positive control, and with CM of HMCLs (JJN3, OPM2, and MM1S) in presence or absence of anti-TNF $\alpha$ neutralizing antibody $(2.7 \mu \mathrm{g} / \mathrm{mL})$. At the end of the experiments, CX3CL1 levels were evaluated by enzyme-linked immunosorbent assay (ELISA) in the supernatants. The histograms represent the mean \pm SD of CX3CL1 levels in two different experiments. (ECs + CM HMCLs vs. Cnt (HUVEC or HBMESC alone): $\left.{ }^{\#} P<0.05\right) .{ }^{\#} P$ values were calculated by two-tailed Student's $t$-test. HUVEC-human umbilical vein endothelial cells; TNF $\alpha$-with tumor necrosis factor alpha; IFN $\gamma$-interferon gamma.

\subsection{CX3CR1 is Expressed by Endothelial Cells}

Since the ECs produce CX3CL1 after pro-inflammatory stimuli from MM cells, we explored the CX3CR1 expression by MM cells and microenvironment cells. We found that HUVECs expressed CX3CR1 at protein levels (Figure 5A). In addition, BM monocytes from MM patients expressed CX3CR1, and, in particular, the subset $\mathrm{CD} 14^{+} \mathrm{CD} 16^{+}$showed a higher expression of the receptor as compared to the $\mathrm{CD} 14^{+} \mathrm{CD} 16^{-}$one $(P=0.0055$, Mann-Whitney test) evaluated as median fluorescence intensity (MFI) by flow cytometry (Figure 5B,C). 
A)

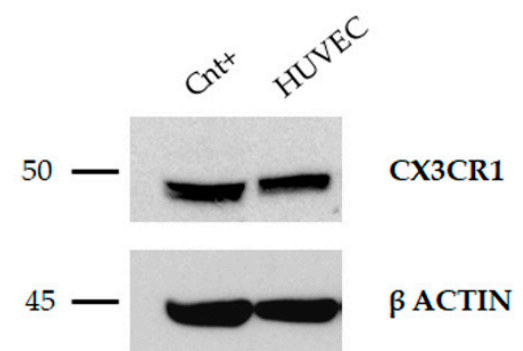

B)
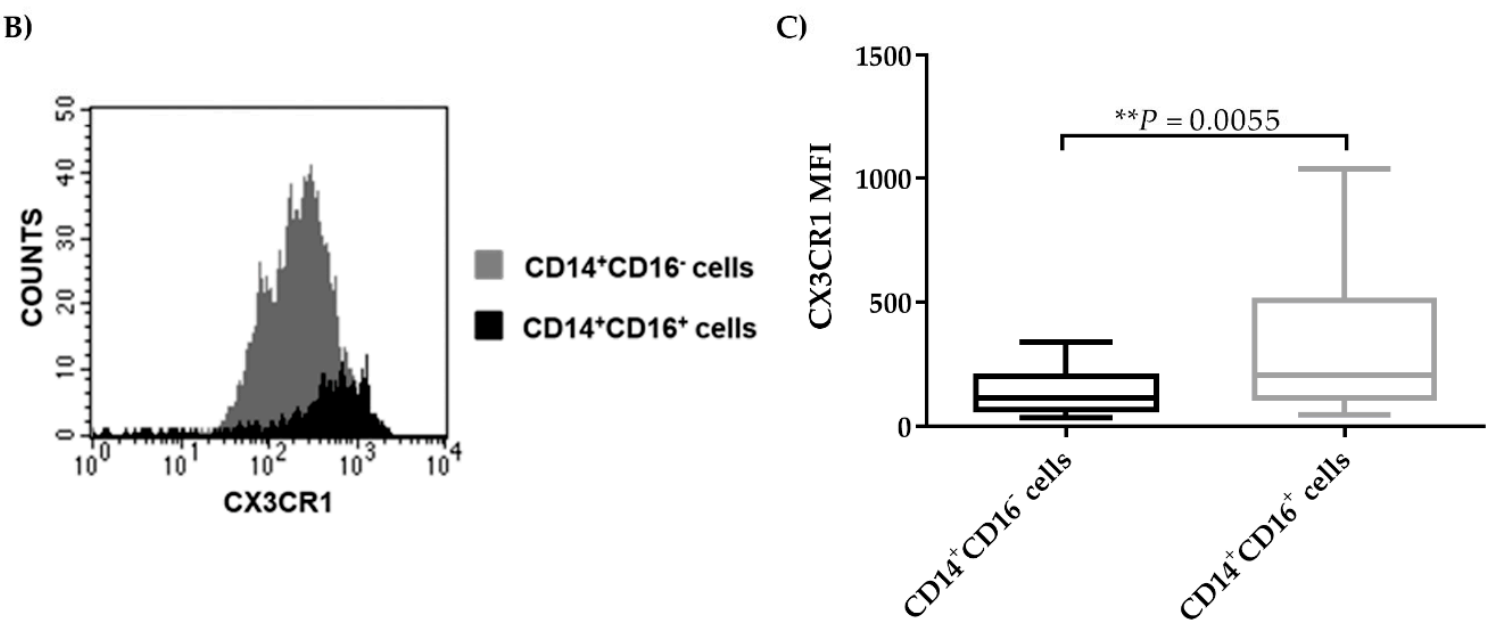

Figure 5. CX3CR1 expression by ECs. (A) Protein expression of CX3CR1 was evaluated by western blot on HUVEC cells (positive control: THP-1 cells). (B) The flow-cytometry histogram shows CX3CR1 expression and median fluorescence intensity (MFI) of $\mathrm{CD}_{14}{ }^{+} \mathrm{CD} 16^{+}$(black) and $\mathrm{CD} 14^{+} \mathrm{CD} 16^{-}$(grey) monocyte subsets in one representative Multiple Myeloma patient (MM)-68. (C) Box plots represent the median level of CX3CR1 MFI in BM CD14 ${ }^{+} \mathrm{CD} 16^{+}$and $\mathrm{CD} 14^{+} \mathrm{CD} 16^{-}$monocytes from $2 \mathrm{MGUS}, 4$ SMM, and $17 \mathrm{MM}$ patients ( $P$ value calculated by Mann-Whitney test).

\subsection{CX3CL1/CX3CR1 Axis is Involved in Both In Vivo and In Vitro Multiple Myeloma-Induced Angiogenesis}

The potential involvement of CX3CL1 in MM-induced angiogenesis was investigated in vivo by chorioallantoic membrane (CAM) assay. As expected, BM plasma from four MM patients induced a significant increase of neo-vessel numbers compared to the negative control MM-11: BM plasma vs. negative control $P=0.0068$; $\mathrm{MM}-22$ : $\mathrm{BM}$ plasma vs. negative control $P=0.011$; $\mathrm{MM}-4$ : $\mathrm{BM}$ plasma vs. negative control $P=0.009$; MM-18: BM plasma vs. negative control $P=0.005$, Student's $t$-test). The treatment with blocking anti-CX3CL1 monoclonal antibody (mAb) significantly reduced this pro-angiogenic activity (MM-6: BM plasma vs. anti-CX3CL1 $P=0.02$; MM-53: BM plasma vs. anti-CX3CL1 $P=0.03$; MM-2: BM plasma vs. anti-CX3CL1 $P=0.02$; MM-10: BM plasma vs. anti-CX3CL1 $P=0.01$, Student's $t$-test) (Figure 6A). Figure 6B shows a representative picture of the CAM assay. 
A)

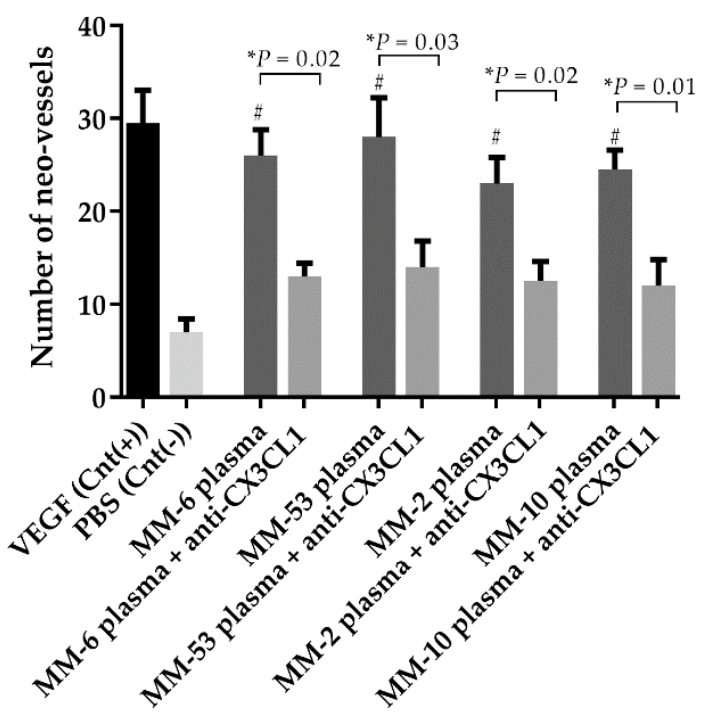

B)
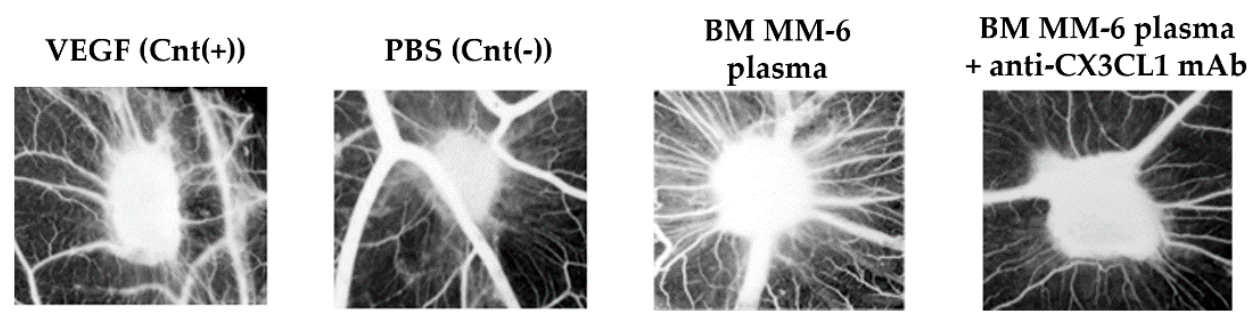

Figure 6. BM plasma from MM patients stimulates angiogenesis in vivo. The chorioallantoic membrane (CAM) assays were performed by treating the chicken chorioallantoic membrane for 12 days with BM plasma from four MM patients with or without anti-CX3CL1 (vascular endothelial growth factor (VEGF)) as positive control and phosphate-buffered saline (PBS) as negative control. (A) The histogram represents the mean \pm SD of number of neo-vessels in CAM treated with BM plasma from four MM patients and with or without anti-CX3CL1 $(0.3 \mu \mathrm{g} / \mathrm{mL})$. (BM plasma vs. negative control: $\left.{ }^{\#} P<0.05\right)$. \# $P$ values were calculated by one-tailed Student's $t$-test. (B) Representative macroscopic pictures of gelatin implanted on the top of chick embryo chorioallantoic membrane of one experiment using BM plasma from MM-11 patient with or without anti-CX3CL1. Original magnification $50 \times$.

On the basis of these results, we then performed an in vitro angiogenesis assay by testing different concentrations of recombinant human (rh) CX3CL1. For this aim, rhCX3CL1 was used at $20 \mathrm{ng} / \mathrm{mL}$, which is known to be the maximum dose able to induce tube formation in HUVEC cells [30], and at concentrations comparable to the lowest $(0.45 \mathrm{ng} / \mathrm{mL})$ and the highest $(2.25 \mathrm{ng} / \mathrm{mL})$ found in our BM samples, in the presence or absence of blocking anti-CX3CL1 mAb (Figure 7A). For all concentrations, the presence of blocking anti-CX3CL1 mAb completely inhibited the ability of CX3CL1 to increase the number of tubular junctions (mean \pm SD: $\mathrm{rhCX3CL1} 20 \mathrm{ng} / \mathrm{mL}$ $3186 \pm 292.3$ vs. anti-CX3CL1 mAb $80 \pm 45.8, P<0.0001 ;$ rhCX3CL1 2.25 ng/mL $418.25 \pm 233.08$ vs. anti-CX3CL1 mAb 55.5 $\pm 22.8, P=0.027$; rhCX3CL1 0.45 ng/mL $288.75 \pm 99.72$ vs. anti-CX3CL1 $\mathrm{mAb} 33 \pm 9.8 P=0.021$, Student's $t$-test) (Figure 7B). All these data confirm the direct involvement of CX3CL1 in MM-induced angiogenesis. 
A)

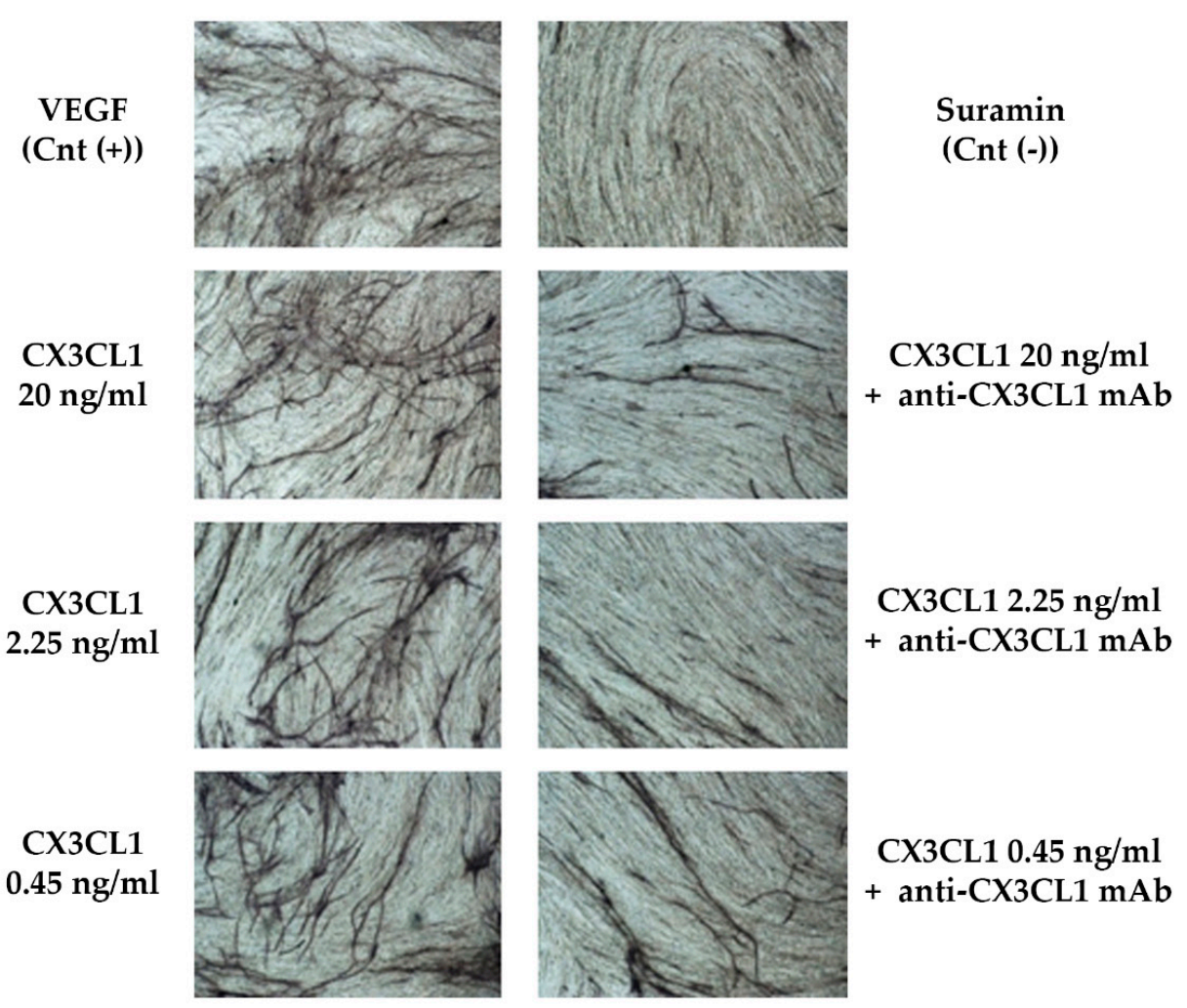

B)

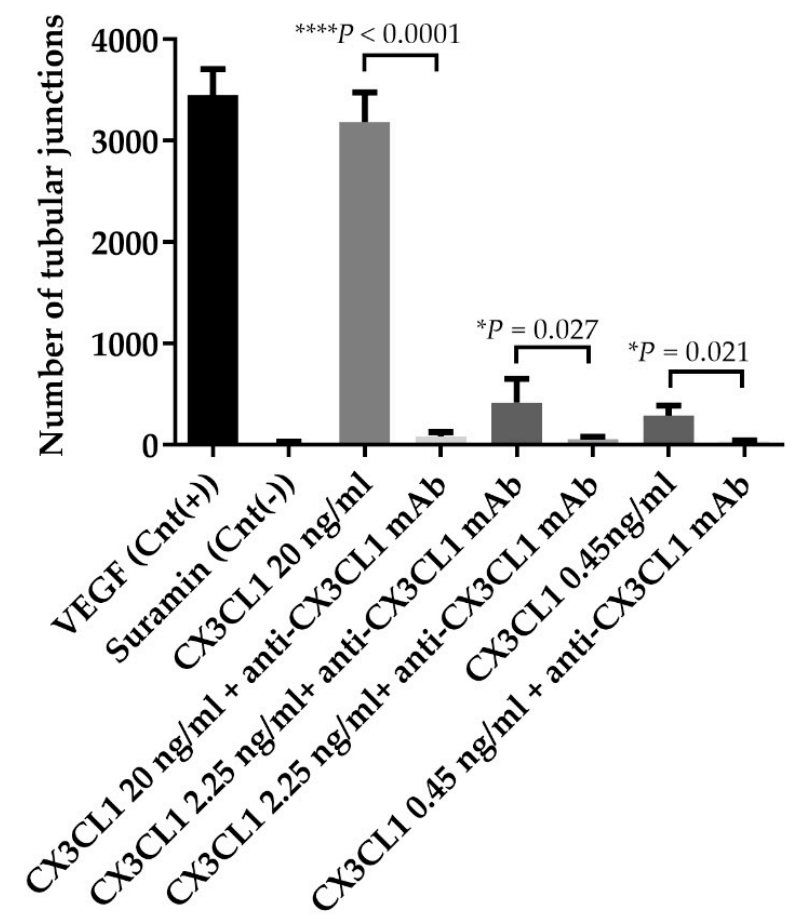

Figure 7. (A) In vitro angiogenic property of CX3CL1. The Angiokit co-culture of HUVEC and fibroblast cells was stimulated for 14 days with the recombinant human (rh) CX3CL1 at different concentrations (ranging $0.45-20 \mathrm{ng} / \mathrm{mL}$ ) in the presence or absence of blocking anti-CX3CL1 monoclonal antibody $(\mathrm{mAb})(0.6 \mu \mathrm{g} / \mathrm{mL})$ (positive control: V2a Growth Medium added with VEGF; negative control: V2a Growth Medium added with suramin). (B) The graph represents the mean \pm SD values of the number of tubular junctions of two replicates ( $P$ values were calculated by two-tailed Student's $t$-test) quantified with Angioquant software. 


\section{Discussion}

The expression of the CX3CL1/CX3CR1 axis in MM cells and their microenvironment was defined in this study. We showed that higher levels of soluble CX3CL1 were present in the BM plasma of MM patients as compared with indolent monoclonal gammopathies. Moreover, we found that the CX3CL1/CX3CR1 axis was mainly involved in the increased BM vascularization and, consequently, in MM-induced angiogenesis.

CX3CL1, also known as fractalkine, is a chemokine found either as a membrane-bound protein or in a soluble form after cleavage by the metalloproteases ADAM10 [12] and ADAM17 [13]. All the biological effects of CX3CL1 are the results of the binding to its receptor CX3CR1 [14]. CX3CL1 is a chemokine that combines chemoattractant and pro-adhesion properties by recruiting cells that express CX3CR1; CX3CL1 exhibits pro-inflammatory properties by its chemotactic activity for NK cells, DCs, monocytes, and mature osteoclasts [31,32]. In addition, soluble CX3CL1 is involved in angiogenesis and endothelial cell chemotaxis [33,34]. CX3CL1 displays pro-angiogenic and pro-inflammatory effects in a number of pathological conditions, including rheumatoid arthritis, diabetes, and cancers $[35,36]$. Indeed, the CX3CL1/CX3CR1 axis is involved in the interaction between tumor cells and the microenvironment by the regulation of tumor cell invasion, migration, and adhesion and promotes bone metastasis [19-22].

Multiple Myeloma is typically characterized by a pro-inflammatory and pro-angiogenic microenvironment that supports MM cell growth and the progression of the disease [37]. However, the role of the CX3CL1/CX3CR1 axis in MM has not yet been explored. Our data indicated the CX3CL1 progressively increased across the monoclonal gammopathies and correlated with the BM MVD and PC infiltration but not with the presence of osteolytic bone disease. Wada et al. described that few HMCLs expressed CX3CR1 and that CX3CL1-treated HMCLs increased osteoclast differentiation [23] accordingly with the role of CX3CL1 in bone resorption [31]. Clearly, the lack of relationship between CX3CL1 BM plasma levels and the presence of bone disease in MM patients excludes the possible role of this chemokine system in MM-induced osteoclastogenesis as reported for other pro-osteoclastogenic cytokines [38]. However, our data clearly indicated that both HMCLs and primary CD138 ${ }^{+}$PCs did not express CX3CR1 mRNA. Consistently, gene and protein expression analysis revealed the absence of CX3CL1 expression by PCs. Our data also indicated that ECs may contribute to the higher BM CX3CL1 levels in MM patients. The levels of BM CX3CL1 positively correlated with both the number of $\mathrm{CD} 34^{+}$vessels and with the percentage of BM PCs in bone biopsies. In agreement with what was reported by others $[39,40]$, ECs stimulated with pro-inflammatory stimuli produced high levels of soluble CX3CL1. In the same way, ECs showed high CX3CL1 production after treatment with CM of several HMCLs supporting the notion that the cross talk between MM and the microenvironment cells stimulated the production of inflammatory cytokines. Indeed, it is well reported that MM cells secreted TNF $\alpha$ [29]. Our in vitro data showed that the treatment with anti-TNF $\alpha$ neutralizing antibody inhibited the MM-mediated production of CX3CL1 indicating the involvement of this well-known pro-inflammatory cytokine. The role of TNF $\alpha$ in the pathophysiology of MM is well established as being a pro-survival factor of MM cells involved in osteoclast activation and angiogenesis [29]. Our study suggests that the pro-angiogenic effect of the MM-derived TNF $\alpha$ could be also mediated by the up-regulation by ECs of CX3CL1 that, in turn, stimulated new vessel formation.

Among the different microenvironment cell types, we then confirmed that ECs expressed CX3CR1. Previous data demonstrated that the angiogenic property of CX3CL1 was mediated by the phosphorylation of extracellular signal-regulated kinases (ERK), Protein kinase B (Akt), and endothelial nitric oxide (NO) synthase (eNOS), as well as an increase in NO production [30]. CX3CL1 also stimulated EC proliferation, migration, and tube formation in vitro and in vivo [41].

Our data in MM patients indicated that, other than the relationship between BM plasma CX3CL1 levels and BM MVD, a statistical correlation between CX3CL1 and the number of BM CD14 ${ }^{+} \mathrm{CD} 16^{+}$ also exists. In a multivariate analysis, we demonstrated that BM CX3CL1 plasma levels correlated with the number of $\mathrm{BM} \mathrm{CD} 14^{+} \mathrm{CD} 16^{+}$. We and others previously reported higher levels of this 
subpopulation of monocytes in MM patients as compared to MGUS patients that are able to generate osteoclasts in vitro $[24,42,43]$. There are many data reporting the pro-angiogenic role of CD14 ${ }^{+} \mathrm{CD} 16^{+}$ non-classical monocytes either in physiological conditions or in the tumor microenvironment [44]. Moreover, it has been reported that CX3CL1 may induce the pro-angiogenic profile of CD14 $4^{+} \mathrm{CD} 16^{+}$ monocytes $[21,45]$ supporting the role of CX3CL1 in the angiogenic process in MM patients. The link between inflammation and angiogenesis is well established and the effect of CX3CL1 treatment on CX3CR1-positive monocytes to stimulate their angiogenic differentiation has been reported [18,21].

Thus, based on the relationship between CX3CL1 soluble levels with the angiogenic properties of MM patients, we next explored the contribution of the CX3CL1/CX3CR1 axis in MM-induced angiogenesis in pre-clinical models. The pro-angiogenic role of CX3CL1 has been investigated in two different models both in vivo and in vitro. In CAM assay, as expected, BM plasma from MM patients increased the neo-angiogenesis effect that was inhibited by the treatment with blocking anti-CX3CL1 mAb. Similarly, rhCX3CL1 stimulated tube formation at concentrations comparable to those found in MM plasma whereas the addition of blocking anti-CX3CL1 mAb inhibited this effect. Overall, these data demonstrated the role of this system in the pro-angiogenic properties of MM cells through the interaction with ECs and the activation of the CX3CL1/CX3CR1 axis.

Our data support the possible role of this system as a potential therapeutic target in MM. Currently, there are no data reporting the use of modulators of the CX3CL1/CX3CR1 axis as anti-angiogenic drugs. However, the anti-inflammatory effect of blocking CX3CL1/CX3CR1 antagonists has been previously reported [46]. A humanized anti-CX3CL1 mAb E6011 has been tested in a phase 1/2 clinical trial in patients with rheumatoid arthritis showing good tolerability and safety [47]. Specifically, it targets the trafficking of immune cells, which produce pro-inflammatory cytokines in the local inflamed sites [47]. Others studies suggested that anti-CX3CL1 mAbs inhibited the migration of CX3CR1+ macrophages and cytotoxic effector $\mathrm{T}$ cells responsible for the production of pro-inflammatory cytokines suggesting their potential role in blocking the inflammation cascade in the local inflamed region [46]. Our data on the role of CX3CL1 in MM-induced angiogenesis support the possible use of the E6011 in MM patients to block the pro-angiogenic and pro-inflammatory activity of CXC3CL1. As known, drugs with anti-angiogenic and anti-inflammatory activity such as thalidomide and proteasome inhibitors are widely used with success in the treatment of MM patients. Interestingly, it was reported that Bortezomib inhibits CX3CL1 production in an inflammatory rat model [48].

In addition, the high-affinity small-molecule inhibitor of CX3CR1 (AZD8797) has been investigated in a rat model of multiple sclerosis where it blocked the infiltration of CX3CR1-expressing cells into the central nervous system [49]. More recently a novel small-molecule CX3CR1 antagonist was developed and tested in a preclinical breast cancer model showing an anti-bone metastatic effect [50]. Our evidence showing the involvement of CX3CL1 in MM-induced angiogenesis, together with the pro-inflammatory bone microenvironment that characterized MM patients [51], gives the rationale to test this possible therapeutic approach by blocking the CX3CL1/CX3R1 axis in MM also.

\section{Materials and Methods}

\subsection{Patient Samples}

A total cohort of 111 patients (56 males and 55 female) with PC disorders were included in the study until September 2018: 16 patients with MGUS (median age: 66 years; range: 42-78), 25 with SMM (median age: 69 years; range: 38-93), and 70 with active MM (median age: 73 years; range: 52-89) including 49 MM-ND and 21 MM-R.

Ten HD were used as controls. All patients were diagnosed according to the International Myeloma Working Group (IMWG) revised criteria [52]. Patients were considered to have bone involvement based on the presence of one or more osteolytic lesions and/or osteoporosis in the skeletal survey, according to the hyperCalcemia, Renal failure, Anemia, Bone lesions (CRAB) criteria. The presence of three or more osteolytic lesions or fractures defined HBD. Patients with a negative skeletal 
survey or a positive skeletal survey with fewer than three osteolytic lesions were considered to have LBD [38]. The main clinical characteristics of all the patients enrolled in the study are summarized in Supplemental Table S1.

Bone Marrow aspirates ( $5+5 \mathrm{~mL}$, treated with EDTA to prevent clotting) and bone biopsies were obtained from the iliac crest of each patient. BM plasma was collected after centrifugation, and stored at $-20{ }^{\circ} \mathrm{C}$ until the analysis. Patient samples were obtained after informed consent, according to the Declaration of Helsinki. The study was included in a project approved by the Institutional Ethical Review Board of Parma Hospital (0006639-6.2.2 of 22 February 2017).

Bone marrow mononuclear cells (MNCs) were obtained after gradient centrifugation with Ficoll solution (Lympholyte ${ }^{\circledR}$ Cell Separation Media, CEDARLANE, ON, Canada). CD138 ${ }^{+}$PCs were isolated from BM MNCs by an immunomagnetic method with anti-CD138 antibody conjugated with microbeads (Miltenyi Biotec, Bergisch Gladbach, Germany) from MM patients, as previously described [53].

\subsection{Immunohistochemistry}

Bone biopsy sections were incubated with mouse anti-human CD138 clone B-A38 (ready to use, Ventana Medical Systems, Tucson, AZ, USA) and the reaction was revealed with polymeric ultraView Universal DAB detection (Ventana Medical Systems) or with rabbit anti-human CD34 (1:100, Santa Cruz Biotechnology, Santa Cruz, CA, USA). After washing, sections were incubated with a secondary antibody (rat anti-Immunoglobulin G horseradish peroxidase (HRP); Millipore, Burlington, MA, USA; 1:250) and the reaction was revealed with a solution of 3,3'-diaminobenzidine tetrahydrochloride (Liquid DAB Substrate Chromogen System, DAKO, Glostrup, Denmark). MVD was evaluated as the number of $\mathrm{CD} 4^{+}$vessels $/ \mathrm{mm}^{2}$ in MM patients' bone biopsies. Images of IHC analyses were captured by a DP22 digital camera (Olympus, Hamburg, Germany) and analyzed with the OLYMPUS Stream software, adjusting tone and contrast to ensure the best image quality.

\subsection{Flow-Cytometry Assay}

After MNC isolation, cells were collected and analyzed by flow cytometry using the following mAbs (BD Biosciences, Milan, Italy): Anti-CD138 R-phycoerythrin (PE) (552026), anti-CD14 Allophycocyanin (APC) (cod. 555399), anti-CD16 fluorescein isothiocyanate (FITC) (cod. 555406), and anti-CX3CR1 PE (cod. 565796). The analyses were performed on a two-laser FACSCalibur instrument (BD Biosciences) using CellQuest software v.4 (BD Biosciences).

\subsection{Analysis of Gene Expression Profiles}

The gene expression profiles of CX3CL1 were evaluated in PCs of 4 HD, 11 MGUS, 133 MM, 9 PCL patients (GSE16122), and 23 HMCLs (GSE6205). The data were extracted from CEL files using a robust multi-array average (RMA) normalization procedure and custom chip definition file (CDF) annotation package (GeneAnnot v2.2.1, Rehovot, Israel), as previously described [54].

\subsection{Cells and Cell Culture Conditions}

\subsubsection{Cell Lines}

The HMCLs JJN3, OPM2, U266, MM1S, NCI-H929, RPMI-8226, and the acute monocytic leukemia (THP-1) cell lines were purchased from Leibniz Institute Deutsche Sammlung von Mikroorganismen und Zellkulturen GmbH (Braunschweig, Germany). The HMCLs XG1 and INA6 were obtained by the Laboratory of INSERM from Dr. Martine Amiot (Nantes, France).

The human bone marrow stromal cell line, HS-5, was purchased from ATCC (Manassas, VA, USA). The human telomerase reverse transcriptase transduced mesenchymal stromal cell line (hTERT-MSCs) was kindly gifted from Dr. Giuseppe Gaipa (Monza, Italy). Immortalized human osteoblast-like (HOBIT) cells were kindly provided from Dr. B. L. Riggs (Rochester, MN, USA). The human 
pre-osteocytic cells (HOB-01) were established from human bone and kindly provided by Julia Billars (Collegeville, PA, USA). HUVEC were obtained by ATCC. The human BM derived endothelial stem cells (HBMESC) were purchased from Celprogen (Torrance, CA, USA) and both were maintained in culture with HBMESC complete growth media with serum (Celprogen) on a flask pre-coated with collagen type 1 (Roche, Basel, Switzerland). All cell lines were authenticated and tested for mycoplasma contamination.

\subsubsection{Cell Conditions and Experimental Procedures}

$\mathrm{CM}$ from HMCLs were collected after $48 \mathrm{~h}$ of culture and stored at $-20{ }^{\circ} \mathrm{C}$ until use. In collagen-coated six-well plates, HUVEC and HBMESC were incubated in the presence or absence of diluted CM (1:3) of OPM2, JJN3, and MM1S for $24 \mathrm{~h}$ and with or without recombinant TNF $\alpha$ (50 ng/mL) (OriGene; Rockville, MD, USA) and/or neutralizing anti-TNF $\alpha$ mAb $(2.7 \mu \mathrm{g} / \mathrm{mL}$ able to neutralize $50 \mathrm{ng} / \mathrm{mL}$ ) (R\&D systems Minneapolis, MN, USA) for $24 \mathrm{~h}$. HUVEC and HBMESC treated with TNF $\alpha(50 \mathrm{ng} / \mathrm{mL})$ and IFN $\gamma(10 \mathrm{ng} / \mathrm{mL})$ (Sigma-Aldrich, Italia, Milan, Italy) for $24 \mathrm{~h}$ were used as a positive control. At the end of the experiment, the culture media were collected and analyzed by enzyme-linked immunosorbent assay (ELISA).

\subsection{ELISA}

Soluble CX3CL1 was measured by ELISA (R\&D System, Minneapolis, MN, USA) in BM plasma samples and in HMCLs, HUVEC, HBMESC, and co-cultured CM, according to the instructions of the manufacturer.

\subsection{Western Blotting Analysis}

Western blotting was performed on the HMCLs (JJN3, OPM2, U266, INA6, XG1, MM1S, and RPMI-8226) and on primary CD138 ${ }^{+}$cells purified from four MM-ND and four MM-R patients, as previously described [55]. Blots were incubated at $4{ }^{\circ} \mathrm{C}$ overnight with the following antibodies: Anti-CX3CL1 (rabbit, polyclonal, 1:1000) and anti- $\beta$-actin (mouse, monoclonal 1:5000) (Sigma-Aldrich) as internal control.

\subsection{Chick Embryo Chorioallantoic Membrane Assay}

Fertilized White Leghorn chicken eggs were incubated at $37^{\circ} \mathrm{C}$ in constant humidity. On day 3 of incubation, a square window was cut in the shell of each egg, and $2-3 \mathrm{~mL}$ of albumen was removed to allow detachment of the developing CAM. The window was sealed with a glass coverslip, and the eggs were returned to the incubator. On day 8 of incubation, the coverslips were removed and the growing CAMs (10 eggs per group) were treated with 1 lL PBS (negative control); $1 \mu \mathrm{L}$ PBS with $250 \mathrm{ng}$ vascular endothelial growth factor (VEGF) (R\&D Systems, positive control); $1 \mu \mathrm{L}$ MM BM plasma treated or not with a neutralizing antibody to CX3CL1 $0.3 \mu \mathrm{g} / \mathrm{mL}$ (R\&D Systems). The coverslips were replaced after these treatments, and the CAMs were examined daily until day 12 of incubation, when they were photographed in ovo using a stereomicroscope equipped with a camera and image analysis system (Olympus Italia, Italy). Blood vessels entering the sponges within the focal plane of the CAM were counted by two observers in a double-blind fashion at a magnification of $50 \times$.

\subsection{Angiogenesis In Vitro Assay}

In vitro angiogenesis was assessed by a V2a angiogenesis assay kit obtained from Cellworks (Buckingham, UK). Endothelial cells were stimulated with VEGF $(2 \mathrm{ng} / \mathrm{mL}$, positive control) or suramin $(20 \mu \mathrm{M}$, negative control) or with recombinant CX3CL1 $(20 \mathrm{ng} / \mathrm{mL}, 2.09 \mathrm{ng} / \mathrm{mL}$, or $0.45 \mathrm{ng} / \mathrm{mL}$ ) or with a neutralizing antibody to CX3CL1 $(0.6 \mu \mathrm{g} / \mathrm{mL})$ (R\&D Systems). At day 14, cells were fixed and stained using an anti-CD31 Ab provided with the V2a angiogenesis assay kit following 
the manual instructions. Angioquant software was used to quantify the number and length of the formed tubules and the number of junctions.

\subsection{Statistical Analysis}

Comparisons among the three groups were made with the Kruskal-Wallis test and pairwise comparisons with the Mann-Whitney test or with parametric unpaired t-test. The Spearman test was used for correlations. Relationships adjusted for potential covariates were examined by multiple linear regression. A $P$ value $<0.05$ was considered significant. GraphPad Prism 6 software was used for all the statistical analyses.

\section{Conclusions}

In conclusion, our data indicate that BM CX3CL1 plasma levels are increased across the progression of monoclonal gammopathies from MGUS to MM and that the high CX3CL1 BM levels in MM correlated with the presence of a high grade of vascularization. The major source of CX3CL1 seems to be ECs that release CX3CL1 in the presence of MM cells with the involvement of the pro-inflammatory cytokine TNF $\alpha$. By both in vitro and ex vivo angiogenic models we finally demonstrated the role of the CX3CL1/CX3R1 axis in the pro-angiogenic switch induced by MM cells. Our results underline the importance of the BM CX3CL1 levels as a possible new biomarker for the progression of MM related to the increase of the BM vascularization. The role of the CX3CL1/CX3CR1 axis as a new possible anti-angiogenic therapeutic target in MM is also suggested by our results.

Supplementary Materials: The following are available online at http:/ / www.mdpi.com/2072-6694/11/3/321/s1, Figure S1: Evaluation of CX3CL1 bone marrow levels in myeloma patients with or without bone disease. Table S1: Clinical characteristics of patients.

Author Contributions: V.M. and M.B. performed all the in vitro experiments, supported by D.T., P.S., and E.V. V.M., D.T., and N.G. analyzed data and wrote the manuscript. A.C., E.F., and R.V. performed the flow-cytometry analysis. B.D.P. and F.A. provide clinical data and patients. C.M. and E.M. performed the histological analysis. D.R. performed the CAM assay and was involved in the interpretation of the results. A.V., V.P., and N.G. read, provided comments, and approved the final version of the manuscript.

Funding: This research was funded in part by a grant from the Associazione Italiana per la Ricerca sul Cancro (IG2017 n. 20299), the International Myeloma Foundation under 2018 Brian D. Novis Senior Research Grant; a fellowship Associazione Italiana contro Leucemie, Linfomi e Mielomi ONLUS, ParmAIL (V.M.) and a fellowship Fondazione Italiana per la Ricerca sul Cancro (ID. 18152) (M.B.).

Acknowledgments: This paper is dedicated to the memory of Vito Pistoia, who recently passed away. Pistoia was a very active and vigorous scientist in the field of cancer research and immunology. He was a real friend, a very kind and gentle person. We thank Mario Pedrazzoni for the statistical analysis support. We thank ParmAIL for the support.

Conflicts of Interest: The authors declare no conflict of interest.

\section{References}

1. Qu, X.; Tang, Y.; Hua, S. Immunological Approaches Towards Cancer and Inflammation: A Cross Talk. Front. Immunol. 2018, 9, 563. [CrossRef] [PubMed]

2. Kumar, S.; Witzig, T.E.; Greipp, P.R.; Rajkumar, S.V. Bone marrow angiogenesis and circulating plasma cells in multiple myeloma. Br. J. Haematol. 2003, 122, 272-274. [PubMed]

3. Menu, E.; Asosingh, K.; Van Riet, I.; Croucher, P.; Van Camp, B.; Vanderkerken, K. Myeloma cells (5TMM) and their interactions with the marrow microenvironment. Blood Cells Mol. Dis. 2004, 33, 111-119. [CrossRef] [PubMed]

4. Giuliani, N.; Rizzoli, V. Myeloma cells and bone marrow osteoblast interactions: Role in the development of osteolytic lesions in multiple myeloma. Leuk. Lymphoma 2007, 48, 2323-2329. [CrossRef] [PubMed]

5. Vacca, A.; Ribatti, D. Bone marrow angiogenesis in multiple myeloma. Leukemia 2006, 20, 193-199. [CrossRef] [PubMed] 
6. Kumar, S.; Witzig, T.E.; Timm, M.; Haug, J.; Wellik, L.; Kimlinger, T.K.; Greipp, P.R.; Rajkumar, S.V. Bone marrow angiogenic ability and expression of angiogenic cytokines in myeloma: Evidence favoring loss of marrow angiogenesis inhibitory activity with disease progression. Blood 2004, 104, 1159-1165. [CrossRef] [PubMed]

7. De Raeve, H.; Van Marck, E.; Van Camp, B.; Vanderkerken, K. Angiogenesis and the role of bone marrow endothelial cells in haematological malignancies. Histol. Histopathol. 2004, 19, 935-950. [CrossRef] [PubMed]

8. Kimlinger, T.; Kline, M.; Kumar, S.; Lust, J.; Witzig, T.; Rajkumar, S.V. Differential expression of vascular endothelial growth factors and their receptors in multiple myeloma. Haematologica 2006, 91, 1033-1040. [PubMed]

9. Kumar, S.; Gertz, M.A.; Dispenzieri, A.; Lacy, M.Q.; Wellik, L.A.; Fonseca, R.; Lust, J.A.; Witzig, T.E.; Kyle, R.A.; Greipp, P.R.; et al. Prognostic value of bone marrow angiogenesis in patients with multiple myeloma undergoing high-dose therapy. Bone Marrow Transplant. 2004, 34, 235-239. [CrossRef] [PubMed]

10. Rajkumar, S.V.; Mesa, R.A.; Fonseca, R.; Schroeder, G.; Plevak, M.F.; Dispenzieri, A.; Lacy, M.Q.; Lust, J.A.; Witzig, T.E.; Gertz, M.A.; et al. Bone marrow angiogenesis in 400 patients with monoclonal gammopathy of undetermined significance, multiple myeloma, and primary amyloidosis. Clin. Cancer Res. 2002, 8, 2210-2216. [PubMed]

11. Liu, W.; Jiang, L.; Bian, C.; Liang, Y.; Xing, R.; Yishakea, M.; Dong, J. Role of CX3CL1 in Diseases. Arch. Immunol. Ther. Exp. 2016, 64, 371-383. [CrossRef] [PubMed]

12. Wong, H.S.; Jaumouille, V.; Heit, B.; Doodnauth, S.A.; Patel, S.; Huang, Y.W.; Grinstein, S.; Robinson, L.A. Cytoskeletal confinement of CX3CL1 limits its susceptibility to proteolytic cleavage by ADAM10. Mol. Biol. Cell 2014, 25, 3884-3899. [CrossRef] [PubMed]

13. Bergmeier, W.; Piffath, C.L.; Cheng, G.; Dole, V.S.; Zhang, Y.; von Andrian, U.H.; Wagner, D.D. Tumor necrosis factor- $\alpha$-converting enzyme (ADAM17) mediates GPIb $\alpha$ shedding from platelets in vitro and in vivo. Circ. Res. 2004, 95, 677-683. [CrossRef] [PubMed]

14. Lu, P.; Li, L.; Kuno, K.; Wu, Y.; Baba, T.; Li, Y.Y.; Zhang, X.; Mukaida, N. Protective roles of the fractalkine/CX3CL1-CX3CR1 interactions in alkali-induced corneal neovascularization through enhanced antiangiogenic factor expression. J. Immunol. 2008, 180, 4283-4291. [CrossRef] [PubMed]

15. Umehara, H.; Bloom, E.; Okazaki, T.; Domae, N.; Imai, T. Fractalkine and vascular injury. Trends Immunol. 2001, 22, 602-607. [CrossRef]

16. Umehara, H.; Goda, S.; Imai, T.; Nagano, Y.; Minami, Y.; Tanaka, Y.; Okazaki, T.; Bloom, E.T.; Domae, N. Fractalkine, a CX3C-chemokine, functions predominantly as an adhesion molecule in monocytic cell line THP-1. Immunol. Cell Biol. 2001, 79, 298-302. [CrossRef] [PubMed]

17. Chen, L.; Liu, G.Q.; Wu, H.Y.; Jin, J.; Yin, X.; Li, D.; Lu, P.R. Monocyte chemoattractant protein 1 and fractalkine play opposite roles in angiogenesis via recruitment of different macrophage subtypes. Int. J. Ophthalmol. 2018, 11, 216-222. [CrossRef] [PubMed]

18. Kumar, A.H.; Martin, K.; Turner, E.C.; Buneker, C.K.; Dorgham, K.; Deterre, P.; Caplice, N.M. Role of CX3CR1 receptor in monocyte/macrophage driven neovascularization. PLoS ONE 2013, 8, e57230. [CrossRef] [PubMed]

19. Liu, P.; Liang, Y.; Jiang, L.; Wang, H.; Wang, S.; Dong, J. CX3CL1/fractalkine enhances prostate cancer spinal metastasis by activating the Src/FAK pathway. Int. J. Oncol. 2018, 53, 1544-1556. [CrossRef] [PubMed]

20. Liu, W.; Liang, Y.; Chan, Q.; Jiang, L.; Dong, J. CX3CL1 promotes lung cancer cell migration and invasion via the Src/focal adhesion kinase signaling pathway. Oncol. Rep. 2019, 41, 1911-1917. [CrossRef] [PubMed]

21. Park, Y.; Lee, J.; Kwak, J.Y.; Noh, K.; Yim, E.; Kim, H.K.; Kim, Y.J.; Broxmeyer, H.E.; Kim, J.A. Fractalkine induces angiogenic potential in CX3CR1-expressing monocytes. J. Leukoc. Biol. 2018, 103, 53-66. [CrossRef] [PubMed]

22. Zheng, J.; Yang, M.; Shao, J.; Miao, Y.; Han, J.; Du, J. Chemokine receptor CX3CR1 contributes to macrophage survival in tumor metastasis. Mol. Cancer 2013, 12, 141. [CrossRef] [PubMed]

23. Wada, A.; Ito, A.; Iitsuka, H.; Tsuneyama, K.; Miyazono, T.; Murakami, J.; Shibahara, N.; Sakurai, H.; Saiki, I.; Nakayama, T.; et al. Role of chemokine CX3CL1 in progression of multiple myeloma via CX3CR1 in bone microenvironments. Oncol. Rep. 2015, 33, 2935-2939. [CrossRef] [PubMed]

24. Bolzoni, M.; Ronchetti, D.; Storti, P.; Donofrio, G.; Marchica, V.; Costa, F.; Agnelli, L.; Toscani, D.; Vescovini, R.; Todoerti, K.; et al. IL21R expressing $\mathrm{CD} 14^{+} \mathrm{CD} 16^{+}$monocytes expand in multiple myeloma patients leading to increased osteoclasts. Haematologica 2017, 102, 773-784. [CrossRef] [PubMed] 
25. Sidibe, A.; Ropraz, P.; Jemelin, S.; Emre, Y.; Poittevin, M.; Pocard, M.; Bradfield, P.F.; Imhof, B.A. Angiogenic factor-driven inflammation promotes extravasation of human proangiogenic monocytes to tumours. Nat. Commun. 2018, 9, 355. [CrossRef] [PubMed]

26. Szukiewicz, D.; Kochanowski, J.; Pyzlak, M.; Szewczyk, G.; Stangret, A.; Mittal, T.K. Fractalkine (CX3CL1) and its receptor CX3CR1 may contribute to increased angiogenesis in diabetic placenta. Mediat. Inflamm. 2013, 2013, 437576. [CrossRef] [PubMed]

27. Ahn, S.Y.; Cho, C.H.; Park, K.G.; Lee, H.J.; Lee, S.; Park, S.K.; Lee, I.K.; Koh, G.Y. Tumor necrosis factor-alpha induces fractalkine expression preferentially in arterial endothelial cells and mithramycin A suppresses TNF- $\alpha$-induced fractalkine expression. Am. J. Pathol. 2004, 164, 1663-1672. [CrossRef]

28. Umehara, H.; Bloom, E.T.; Okazaki, T.; Nagano, Y.; Yoshie, O.; Imai, T. Fractalkine in vascular biology: From basic research to clinical disease. Arter. Thromb. Vasc. Biol. 2004, 24, 34-40. [CrossRef] [PubMed]

29. Delgado-Calle, J.; Anderson, J.; Cregor, M.D.; Hiasa, M.; Chirgwin, J.M.; Carlesso, N.; Yoneda, T.; Mohammad, K.S.; Plotkin, L.I.; Roodman, G.D.; et al. Bidirectional Notch Signaling and Osteocyte-Derived Factors in the Bone Marrow Microenvironment Promote Tumor Cell Proliferation and Bone Destruction in Multiple Myeloma. Cancer Res. 2016, 76, 1089-1100. [CrossRef] [PubMed]

30. Lee, S.J.; Namkoong, S.; Kim, Y.M.; Kim, C.K.; Lee, H.; Ha, K.S.; Chung, H.T.; Kwon, Y.G.; Kim, Y.M. Fractalkine stimulates angiogenesis by activating the Raf-1/MEK/ERK- and PI3K/Akt/eNOS-dependent signal pathways. Am. J. Physiol. Heart Circ. Physiol. 2006, 291, H2836-H2846. [CrossRef] [PubMed]

31. Koizumi, K.; Saitoh, Y.; Minami, T.; Takeno, N.; Tsuneyama, K.; Miyahara, T.; Nakayama, T.; Sakurai, H.; Takano, Y.; Nishimura, M.; et al. Role of CX3CL1/fractalkine in osteoclast differentiation and bone resorption. J. Immunol. 2009, 183, 7825-7831. [CrossRef] [PubMed]

32. Guo, J.; Chen, T.; Wang, B.; Zhang, M.; An, H.; Guo, Z.; Yu, Y.; Qin, Z.; Cao, X. Chemoattraction, adhesion and activation of natural killer cells are involved in the antitumor immune response induced by fractalkine/CX3CL1. Immunol. Lett. 2003, 89, 1-7. [CrossRef]

33. Fong, A.M.; Erickson, H.P.; Zachariah, J.P.; Poon, S.; Schamberg, N.J.; Imai, T.; Patel, D.D. Ultrastructure and function of the fractalkine mucin domain in $\mathrm{CX}_{3} \mathrm{C}$ chemokine domain presentation. J. Biol. Chem. 2000, 275, 3781-3786. [CrossRef] [PubMed]

34. El-Shazly, A.E.; Doloriert, H.C.; Bisig, B.; Lefebvre, P.P.; Delvenne, P.; Jacobs, N. Novel cooperation between CX3CL1 and CCL26 inducing NK cell chemotaxis via CX3CR1: A possible mechanism for NK cell infiltration of the allergic nasal tissue. Clin. Exp. Allergy 2013, 43, 322-331. [CrossRef] [PubMed]

35. Ferretti, E.; Pistoia, V.; Corcione, A. Role of fractalkine/CX3CL1 and its receptor in the pathogenesis of inflammatory and malignant diseases with emphasis on B cell malignancies. Mediat. Inflamm. 2014, 2014, 480941. [CrossRef] [PubMed]

36. Zhang, J.L.; Yang, W.L.; Hu, B.Q.; Wu, W.; Fallon, M.B. Endothelin-1 Activation of the Endothelin B Receptor Modulates Pulmonary Endothelial CX3CL1 and Contributes to Pulmonary Angiogenesis in Experimental Hepatopulmonary Syndrome. Am. J. Pathol. 2014, 184, 1706-1714. [CrossRef] [PubMed]

37. Aggarwal, R.; Ghobrial, I.M.; Roodman, G.D. Chemokines in multiple myeloma. Exp. Hematol. 2006, 34, 1289-1295. [CrossRef] [PubMed]

38. Palma, B.D.; Guasco, D.; Pedrazzoni, M.; Bolzoni, M.; Accardi, F.; Costa, F.; Sammarelli, G.; Craviotto, L.; De Filippo, M.; Ruffini, L.; et al. Osteolytic lesions, cytogenetic features and bone marrow levels of cytokines and chemokines in multiple myeloma patients: Role of chemokine (C-C motif) ligand 20. Leukemia 2016, 30, 409-416. [CrossRef] [PubMed]

39. Garton, K.J.; Gough, P.J.; Blobel, C.P.; Murphy, G.; Greaves, D.R.; Dempsey, P.J.; Raines, E.W. Tumor necrosis factor-alpha-converting enzyme (ADAM17) mediates the cleavage and shedding of fractalkine (CX3CL1). J. Biol. Chem. 2001, 276, 37993-38001. [CrossRef] [PubMed]

40. Tsou, C.L.; Haskell, C.A.; Charo, I.F. Tumor necrosis factor-alpha-converting enzyme mediates the inducible cleavage of fractalkine. J. Biol. Chem. 2001, 276, 44622-44626. [CrossRef] [PubMed]

41. You, J.J.; Yang, C.H.; Huang, J.S.; Chen, M.S.; Yang, C.M. Fractalkine, a CX3C chemokine, as a mediator of ocular angiogenesis. Investig. Ophthalmol. Vis. Sci. 2007, 48, 5290-5298. [CrossRef] [PubMed]

42. Chiu, Y.G.; Shao, T.; Feng, C.; Mensah, K.A.; Thullen, M.; Schwarz, E.M.; Ritchlin, C.T. CD16 (FcR $\gamma$ III) as a potential marker of osteoclast precursors in psoriatic arthritis. Arthritis Res. Ther. 2010, 12, R14. [CrossRef] [PubMed] 
43. Sponaas, A.M.; Moen, S.H.; Liabakk, N.B.; Feyzi, E.; Holien, T.; Kvam, S.; Groseth, L.A.; Stordal, B.; Buene, G.; Espevik, T.; et al. The proportion of $\mathrm{CD} 16^{+} \mathrm{CD} 14^{\mathrm{dim}}$ monocytes increases with tumor cell load in bone marrow of patients with multiple myeloma. Immun. Inflamm. Dis. 2015, 3, 94-102. [CrossRef] [PubMed]

44. Lee, H.W.; Choi, H.J.; Ha, S.J.; Lee, K.T.; Kwon, Y.G. Recruitment of monocytes/macrophages in different tumor microenvironments. Biochim. Biophys. Acta 2013, 1835, 170-179. [CrossRef] [PubMed]

45. Ancuta, P.; Rao, R.; Moses, A.; Mehle, A.; Shaw, S.K.; Luscinskas, F.W.; Gabuzda, D. Fractalkine preferentially mediates arrest and migration of CD16 ${ }^{+}$monocytes. J. Exp. Med. 2003, 197, 1701-1707. [CrossRef] [PubMed]

46. Imai, T.; Yasuda, N. Therapeutic intervention of inflammatory/immune diseases by inhibition of the fractalkine (CX3CL1)-CX3CR1 pathway. Inflamm. Regen. 2016, 36, 9. [CrossRef] [PubMed]

47. Tanaka, Y.; Takeuchi, T.; Umehara, H.; Nanki, T.; Yasuda, N.; Tago, F.; Kawakubo, M.; Kitahara, Y.; Hojo, S.; Kawano, T.; et al. Safety, pharmacokinetics, and efficacy of E6011, an antifractalkine monoclonal antibody, in a first-in-patient phase $1 / 2$ study on rheumatoid arthritis. Mod. Rheumatol. 2018, 28, 58-65. [CrossRef] [PubMed]

48. Chen, F.T.; Liu, Y.C.; Yang, C.M.; Yang, C.H. Anti-inflammatory effect of the proteasome inhibitor bortezomib on endotoxin-induced uveitis in rats. Investig. Ophthalmol. Vis. Sci. 2012, 53, 3682-3694. [CrossRef] [PubMed]

49. Ridderstad Wollberg, A.; Ericsson-Dahlstrand, A.; Jureus, A.; Ekerot, P.; Simon, S.; Nilsson, M.; Wiklund, S.J.; Berg, A.L.; Ferm, M.; Sunnemark, D.; et al. Pharmacological inhibition of the chemokine receptor CX3CR1 attenuates disease in a chronic-relapsing rat model for multiple sclerosis. Proc. Natl. Acad. Sci. USA 2014, 111, 5409-5414. [CrossRef] [PubMed]

50. Shen, F.; Zhang, Y.; Jernigan, D.L.; Feng, X.; Yan, J.; Garcia, F.U.; Meucci, O.; Salvino, J.M.; Fatatis, A. Novel Small-Molecule CX3CR1 Antagonist Impairs Metastatic Seeding and Colonization of Breast Cancer Cells. Mol. Cancer Res. 2016, 14, 518-527. [CrossRef] [PubMed]

51. Musolino, C.; Allegra, A.; Innao, V.; Allegra, A.G.; Pioggia, G.; Gangemi, S. Inflammatory and Anti-Inflammatory Equilibrium, Proliferative and Antiproliferative Balance: The Role of Cytokines in Multiple Myeloma. Mediat. Inflamm. 2017, 2017, 1852517. [CrossRef] [PubMed]

52. Rajkumar, S.V.; Dimopoulos, M.A.; Palumbo, A.; Blade, J.; Merlini, G.; Mateos, M.V.; Kumar, S.; Hillengass, J.; Kastritis, E.; Richardson, P.; et al. International Myeloma Working Group updated criteria for the diagnosis of multiple myeloma. Lancet Oncol. 2014, 15, e538-e548. [CrossRef]

53. Bolzoni, M.; Chiu, M.; Accardi, F.; Vescovini, R.; Airoldi, I.; Storti, P.; Todoerti, K.; Agnelli, L.; Missale, G.; Andreoli, R.; et al. Dependence on glutamine uptake and glutamine addiction characterize myeloma cells: A new attractive target. Blood 2016. [CrossRef] [PubMed]

54. Agnelli, L.; Mosca, L.; Fabris, S.; Lionetti, M.; Andronache, A.; Kwee, I.; Todoerti, K.; Verdelli, D.; Battaglia, C.; Bertoni, F.; et al. A SNP microarray and FISH-based procedure to detect allelic imbalances in multiple myeloma: An integrated genomics approach reveals a wide gene dosage effect. Genes Chromosomes Cancer 2009, 48, 603-614. [CrossRef] [PubMed]

55. Storti, P.; Marchica, V.; Airoldi, I.; Donofrio, G.; Fiorini, E.; Ferri, V.; Guasco, D.; Todoerti, K.; Silbermann, R.; Anderson, J.L.; et al. Galectin-1 suppression delineates a new strategy to inhibit myeloma-induced angiogenesis and tumoral growth in vivo. Leukemia 2016. [CrossRef] [PubMed]

(C) 2019 by the authors. Licensee MDPI, Basel, Switzerland. This article is an open access article distributed under the terms and conditions of the Creative Commons Attribution (CC BY) license (http://creativecommons.org/licenses/by/4.0/). 